\title{
Algumas reflexões para estabelecer a cronologia do "fenômeno transexual" (1910-1995)
}

Pierre-Henri Castel CNRS

\section{RESUMO}

O "fenômeno transexual" (Benjamin) é um indicador muito seguro das modificações históricas da percepção científica, mas também cultural e política da identidade sexual no século XX. Para apresentar uma cronologia e uma bibliografia escolhida desse fenômeno, este artigo propõe um fio condutor: a recusa sistemática das interpretações psicanalíticas do transexualismo pelos sexólogos, endocrinologistas e sociólogos que estudaram o problema. Palavras-chave: transexualismo; psicanálise; epistemologia.

\begin{abstract}
The "Transsexual Phenomenon" (Benjamin) is a reliable index of the historical modifications of scientific, cultural and political perception of sexual identity in the 20th century. As an introduction to a chronology and selected bibliography of this phenomenon, I suggest a clue: the systematic denial of the relevance of psychoanalytic explanations of transsexualism by all the biologists, endocrinologists and sociologists who dealt with the problem.
\end{abstract}

Keywords: transsexualism; psychoanalysis; epistemology.

O transexualismo é uma síndrome complexa, cuja inserção na patologia foi, ao final de um processo aqui retraçado, colocada em questão com maior ou menor sucesso. Caracteriza-se pelo sentimento intenso de não-pertença ao sexo anatômico, sem por isso manifestar distúrbios delirantes (a impressão de sofrer uma metamorfose sexual é banal na esquizofrenia, mas neste caso é acompanhada de alucinações diversas), e sem bases orgânicas (como o hermafroditismo ou qualquer outra anomalia endócrina). Esta síndrome foi individualizada em sua forma moderna por um médico alemão emigrado aos Estados Unidos, Harry Benjamin (18851986), e após, sob diversas formas, pouco a pouco admitida nas nosografias psiquiátricas. Ela figura hoje no manual-diagnóstico publicado pela 
Associação Americana de Psiquiatria (DSM 4), não sob o título de "transexualismo", mas como "distúrbio de identidade de gênero". Que o "gênero" possa minimamente parecer uma noção mais clara que a de "sexo" consagra o triunfo em psiquiatria de uma concepção sociológica particular da identidade, e por si só esse fato exige uma análise.

Ora, a possibilidade técnica de satisfazer as demandas de "adequação" vindas dos transexuais, graças aos hormônios e aos progressos da cirurgia plástica, contribuiu para dar ao transexualismo, a partir dos anos 50, uma coloração distinta das descrições mais antigas (por exemplo, as de Krafft-Ebing e Moll, em sua Psychopathia sexualis ${ }^{1}$ ). Desde então, a liberdade de escolha do sexo vem em primeiro plano, como possibilidade de "construção de identidade" sexual e de obter-se para ela a sanção social com os direitos referentes (casamento, inseminação artificial ou de parceria, adoção), acompanhada de uma denúncia dos obstáculos a essa escolha que mobiliza para fins militantes, freqüentemente com sucesso, os instrumentos habituais da crítica dos preconceitos (como a sociologia comparada, que acentuou, no feminismo recente, a distinção entre o "gênero" sociocultural e o "sexo" natural, bem como diversos argumentos biológicos que relativizam o "dimorfismo" homem/mulher).

78 De uma situação individual de início absolutamente marginal, passou-se assim, como o atestam todas as estatísticas dos países desenvolvidos, a um crescimento exponencial de demandas de "mudança de sexo" e a sex ratio, que inicialmente guardava uma proporção de uma mulher para oito homens solicitando hormônios e cirurgia, é agora de uma para três ${ }^{2}$.

Bernice Hausman, em Changing Sex: Transsexualism, Technology and the Idea of Gender ${ }^{3}$, apresenta uma análise histórica esclarecedora da gênese do "fenômeno transexual", segundo a fórmula famosa de Harry Benjamin ${ }^{4}$. Opondo-se às visões militantes que a tomam como emergência de uma forma de liberdade (senão de um "direito do homem"), severamente reprimida pelo sexismo prenhe de representações médicas, ela demonstrou bem como a reivindicação transexual desenvolveu-se numa dialética sutil entre a oferta tecnológica (a dos endocrinologistas e cirurgiões movidos pela compaixão, mas também preocupados em testar hipóteses sobre a natureza humana e suas determinações biológicas) e uma demanda de cuidados mais e mais estruturada por um discurso padronizado, oferecendo aos médicos a imagem exata do que eles esperavam de seus doentes, e repetindo estereótipos transmitidos numa subcultura transexual, validando e estabilizando esta situação como digna do interesse dos médicos. Incluindo a tecnologia médica em sua análise, ela refuta portanto 
o primado da economia do discurso sobre o real do corpo, quando se trata de analisar o transexualismo. Ela se desmarca assim dos feministas, notadamente Judith Butler, em Bodies that matters ${ }^{5}$, que se interessaram por gênero, a ponto de pensar que a noção de sexo, longe de ser uma rocha inabalável (o real biológico suposto fora do discurso, e que é colocado em forma pelo discurso como uma matéria), era um artefato desse discurso: em outras palavras, um real produzido discursivamente (como o limite ideal mais contingente da recategorização sempre possível de nossas representações do "gênero" ou do "sexo"). Para Bernice Hausman, tal visão do sexo é incapaz de dar conta da história positiva do saber biológico, e da inércia que impõe à reconfiguração de nossas idéias sobre o gênero e o sexo a dificuldade intrínseca que existe em mobilizar os meios materiais da realização para deslocar essas categorias - em resumo, à relativização real do dimorfismo homem/mulher. Sem contestar o fundamento da argumentação construtivista de Judith Butler, ela entende portanto dar-lhe o lastro de uma referência materialista à praxis efetiva da medicina.

A história do transexualismo no século XX, na senda da história das idéias, da medicina e dos costumes é, por consequinte, uma tarefa ainda por fazer, de tal modo as questões preliminares de método parecem radicalizar-se diante da singularidade do objeto e da dificuldade de saber do que, de fato, se faz a história. Evidentemente, decidir que não se deve aqui fazer senão a história das representações, numa veia foucaldiana, seria já predefinir o objeto para ajustá-lo à idéia que se faz da história. Também, mais modestamente, gostaria de introduzir aqui uma cronologia preliminar dos textos e fatos mais marcantes na emergência deste problema médico-sociológico, sugerindo uma outra linha de análise do "fenômeno transexual”, ligado às suas condições ideológicas de afirmação nos campos social e científico. Ela não é de forma alguma incompatível com a hipótese de Bernice Hausman, mas permite talvez mensurar melhor os pressupostos conceituais que tendem a fixar as posições contemporâneas numa espécie de contradição mútua que mascara o que elas têm em comum, e as obriga com freqüência a se sustentar logicamente de maneira circular. De fato, o conjunto das teorias (aparentemente tão conflitantes) do transexualismo, pode ser pensado em oposição constante a um corpo de doutrina sobre a sexualidade e a vida psíquica, que é, desde a origem, o inimigo dos partidários da autonomia nosológica, mas também, no outro lado do espectro, do valor cultural e político subversivo da mudança de sexo (ou sua visão pós-moderna, a "construção do gênero"). Este ini- 
migo é a psicanálise. Refutar sua pretensão a explicar o transexualismo é o fio condutor de elaborações teóricas que são tanto as dos partidários de uma etiologia somática da síndrome (e que tem por conseqüência a idéia de que a única terapia é ministrar hormônios e operar os pacientes, não de questionar suas impressões) quanto as dos militantes para quem o direito à autodeterminação da identidade sexual depende de escolha política.

Para mostrar a incidência desta polêmica antipsicanalítica sobre a estruturação do transexualismo, sobre sua forma discursiva, proponho periodizar sua história científica e cultural em quatro fases.

A primeira nos faz remontar às origens da sexologia, em Magnus Hirschfeld, origens indissociavelmente científicas (com uma ambição taxonômica positivista) e militantes, pois a despenalização da homossexualidade sempre constituiu seu alvo (alvo conscientemente procurado), porquanto é um dos alvos da sexologia nascente, quer tenham sido eles homossexuais, quer tenham rejeitado as prevenções da época contra a homossexualidade). A virada freudiana da sexologia, pelos motivos que iremos ver, sempre lhes pareceu infletir seus esforços num sentido alheio a seu projeto.

80 A segunda fase acompanha o desenvolvimento da endocrinologia, que é um dos fatos fundamentais da medicina científica entre as duas guerras. Ela vê o nascimento do que chamarei aqui o "behaviorismo endocrinológico", que de imediato vai tentar pregar uma peça à psicanálise. Ele fundamentalmente preparou a aceitação da maior parte das teses sociológicas sustentadas após 1945 sobre a identidade sexual, e que irão tornar possível o "fenômeno transexual".

A terceira fase, que vai de 1945 a 1975, é a mais rica em acontecimentos. A tradição americana de sociologia empírica e sua teoria da influência determinante do meio vai conduzir muitos pesquisadores a explorar conjuntamente a questão da socialização dos hermafroditas, dos indivíduos geneticamente anormais, dos meninos com órgãos genitais acidentalmente mutilados, e dos transexuais. A mediatização do caso Jorgensen, GI feminizado em 1952, ilumina todo o período fornecendo um cenário padrão inúmeras vezes recopiado e/ou revivido pelos futuros candidatos à mudança de sexo. A psicanálise americana, medicalizada à força, marcada pelo culturalismo, pareceu então impotente para evitar de servir de caução à sociologia do gênero, e perdeu a batalha sem conseguir defender, por razões epistemológicas fundamentais, o caráter patológico de um distúrbio de identidade sexual puramente subjetivo. 
A quarta fase se abre, no meio dos anos 70, com a reivindicação libertária de uma despatologização radical do transexualismo, e a idéia de que a identidade sexual é em si um preconceito e limita a liberdade individual. A rejeição da psicanálise atinge então um tal grau que mesmo a idéia de uma solução psicoterapêutica do transexualismo não está longe de passar por uma fraude ou por um assassinato da liberdade. Simetricamente, o transexualismo está de mais a mais descrito como neuroendocrinológico, por oposição a toda forma de psicogênese (e sobretudo psicanalítica). O "transgenerismo" (transgender), que reúne as aspirações tanto dos transexuais quanto dos transvestistas e de certos homossexuais de apresentação deliberadamente ambígua, cristaliza então as aspirações militantes e as teorias culturais do gênero, fazendo portanto (apesar das aparências) boa convivência com as versões mais biologizantes do "distúrbio da identidade de gênero".

O historiador das idéias valoriza os ciclos, verdadeiros ou supostos, e por isso assinalo aqui que ocorre uma espécie de retorno às origens sexológicas alemãs (e mesmo berlinenses) da problemática transexual: combinação lúdica e festiva, provocante, de trajetórias de vida em que o drama e os sofrimentos interiores diluem-se um pouco na redenção militante, e confiança numa ciência que transporta no cérebro, portanto na natureza, o peso da culpa com que a sociedade oprime injustamente os anormais: sobre um século de psicanálise, e a dominação relativa do paradigma de uma sexualidade intrapsíquica conflituosa, Magnus Hirschfeld triunfa.

A boemia berlinense de antes da Grande Guerra oferecia um terreno de pesquisa somente hoje dimensionado em seu caráter determinante de opções libertárias da sexologia. O primeiro livro onde é usado o termo "transexual" é o que Magnus Hirschfeld lhe consagrou, Die Tranvestiten, em 1910. Como se vê no título, não se trata de separar o transexualismo (a palavra figura, de resto, inserida na expressão "transexual psíquico”) do conjunto das perversões, mas sobretudo, de um lado, de separar as formas de homossexualidade, e de outro, de estabelecer que o transvestismo não é uma prática especificamente homossexual, em via de destruir a homogeneidade aparente da categoria de "atos contra a natureza". De fato, esses eram reprimidos com uma crueldade muito particular pelo Código Imperial de 1870, que retomava nessa matéria disposições aplicadas na Alemanha do Norte antes da unificação. Por trás da sexologia nascente, entre os membros tão diversos de suas primeiras associações científicas internacionais como Havelock Ellis, Auguste Sorel ou Sigmund Freud, a 
lei alemã era um exemplo de barbárie por recusar aos indivíduos consentidores e em privacidade, o que não era dificuldade, na época, em nenhuma parte da Europa (em todo caso, sob reserva da proteção dos menores, não na França ou no Reino-Unido).

Não se pode analisar as estratégias científico-discursivas dos sexólogos fin de siècle, assinalando sua dívida para com o neo-darwinismo spenceriano e os ideais que a reprodução heterossexual, biologicamente indispensável, permite com pouco ônus introduzir em matéria tão sulfurosa, sem ceder ao positivismo descritivo, nem ao amoralismo que ele transmite. Dever-se-ia também compreender que a analítica refinada, ou a subdivisão quase linneana, das múltiplas "aberrações do instinto genésico", que é a substância dessas obras, naturaliza com força retórica irresistível o que poderia bem parecer decorrência de simples vício moral. A estabilidade formal e a regularidade a-histórica das perversões denuncia logo $a$ priori os perversos, para os que sabem ler, de uma responsabilidade qualquer: se não há "atos contra a natureza", é porque a natureza está presente em toda parte, mesmo em suas manifestações mórbidas, e porque o ato é imputado convencionalmente pela justiça penal, lá onde se trata antes de tudo de impulsos irrefreáveis.

É evidente que a impossibilidade de colocar limites ao lícito e ao proibido que refletem qualquer recorte objetivo dos comportamentos humanos está já sendo elaborada por Krafft-Ebing, Moll, Ellis ou Hirschfeld. Trata-se de um procedimento de relativização, de início inocentemente epistemológico, mas finalmente ético, constando de todos os trabalhos sobre a perversão; o "construtivismo social" atual apenas o radicalizou. De outro lado, se a referência última à degenerescência permanece a chave de todas as etiologias da perversão, ela permite também, como em diversas teorias psicopatológicas da época, dar livremente a palavra aos doentes, e respeitar seu vivido subjetivo pelo que ele é, em sua "necessidade fatal" própria.

Dessa forma, foram os dois sexólogos mais desacreditados do fim do século XIX, Kraft-Ebing, depois, com sua morte, seu aluno Moll, que recolheram a auto-observação pungente desse médico transexual anônimo, cuja evolução eles observaram por dezenas de anos, e do qual alguns propósitos poderiam sair palavra por palavra da boca dos doentes contemporâneos - com a notável diferença que introduz a oferta técnica de um "tratamento" hormonal e cirúrgico inimaginável por ele 6 . Até hoje, os psicanalistas se perguntam em qual medida esse médico poderia ser comparado ao presidente Schreber, tal como Freud o compreende, que no qua- 
dro de uma psicose paranóica comprovada havia também manifestado o desejo de uma transformação corporal. Um transexual seria um delirante cuja única manifestação comportamental fácil de objetivar é a esperança de mudar de sexo? Ou seria uma pessoa que manifesta um desejo não-patológico, mas acolhido pela sociedade de modo tal que ele se torna por vezes mentalmente doente?

Compreende-se então quanto o novo rumo freudiano da clínica sexológica, tal como se apresenta em 1905 em Drei Abhandlungen zur Sexualtheorie, aparece ao mesmo tempo como suporte à credibilidade naturalista do empreendimento, e como uma ameaça aos fins sociais e jurídicos (os explícitos e os secretos). Por outro lado, à medida que as bases empíricas da psicanálise pareciam mais frágeis, ela não encontra nenhum socorro nos sexólogos (os quais, com exceção de Ellis, tinham interesses psicológicos bem mais amplos que seus confrades). Pelo contrário, Freud foi logo reconhecido como o promotor de uma nova normatividade hostil às intenções libertárias dos sexólogos, porque ele desprezava a neutralidade descritiva e postulava mecanismos psíquicos à origem das perversões. Isto não podia encorajar no público especialista ou leigo a interpretação deficitária da sexualidade desviante. Ora, sejam quais forem as defesas e as precauções de Freud, seu senso agudo da inutilidade de condenar medicalmente a homossexualidade, é patente que suas teorias abrigam uma norma heterossexual "edipiana” própria a suscitar uma tal inquietação.

Um outro fator é verdadeiramente crucial. A psicanálise pareceu apropriar-se de seus próprios fins, e mesmo, nos ignorantes, criar de seu próprio fundo idéias que haviam sido penosamente implantadas pela ciência do sexo, no fim do século XIX nas consciências cultivadas (a bissexualidade psíquica, ou a sexualidade infantil como fatos universais). Ela lhes deu evidentemente uma difusão extraordinária e as incorporou à cultura moderna. Mas era em benefício de uma idéia do homem, não de uma idéia da liberdade. Havia portanto em germe um desacordo sobre a questão do que é cientificamente o sexo, desacordo que não cessará mais de se ampliar.

Longe de ser a psicologia hegemônica descrita às vezes nos Estados Unidos, entre as duas guerras, a psicanálise sempre teve que combater um adversário de peso, o behaviorismo. Porém, o conflito real (por oposição ao conflito tal como é ideologicamente compreendido e vivido por seus atores) tem uma dimensão sociológica que a pesquisa histórica feminista recente evidenciou. De início, com efeito, o promotor da psicanálise e do 
behaviorismo de Watson (em Johns Hopkins, que é verdadeiramente o centro nevrálgico das teorias sociais da identidade), é Adolf Meyer, o pai da psiquiatria americana. Sensível aos ideais pragmáticos e à sua inscrição social (no campo da pedagogia, por exemplo com Dewey), Meyer procura quebrar o sentimento de fatalidade terapêutica que reina então em medicina mental, em que a teoria da degenerescência dominava sem dividir as opiniões; ora, psicanálise ou behaviorismo, as duas novas correntes prometem uma ação possível e uma modificação radical das vivências mórbidas; Meyer espera portanto fazê-los colaborar. Isto sem contar a desconfiança dos meios médicos, como dos grandes psicólogos experimentalistas americanos, em relação a uma teoria psicológica complexa, infinitamente menos estável que o behaviorismo, como a de Freud.

Ora, nos anos 20 e 30, a progressiva descoberta dos hormônios e a alternativa biológica que eles oferecem à teoria da libido, da bissexualidade e da escolha do papel sexual segundo o Édipo, vai suscitar um entusiasmo extraordinário tanto entre os especialistas quanto no público. $\mathrm{O}$ "behaviorismo endocrinal" de Louis Berman ou de Williams Robinson retoma os temas clássicos desde Brown-Séquard e Starling, no século XIX, do prolongamento da duração da vida e da "segunda juventude" (cujas conotações sexuais não são de forma alguma silenciadas) ${ }^{7}$. Ele dá sua base científica ao dimorfismo e consolida os preconceitos politicamente interessados na diferença homem/mulher, sem recorrer às duvidosas análises introspectivas. É nesse mesmo período, de fato, que são votadas as famosas leis sobre os costumes e o casamento, que são o pano de fundo moral de leis ulteriores sobre a proibição do álcool e as quotas de imigração.

Graças aos hormônios a anormalidade das condutas e dos sentimentos torna-se uma questão de dosagem sangüínea. Retificar essas dosagens é econômico, causalmente eficaz, e deixa fora do campo consciência moral e vida privada. A evidência segundo a qual os comportamentos sexuais ou sociais (sobretudo a violência) dependem dos hormônios não espera senão uma teoria que reduza a identidade pessoal à soma das interações comportamentais para acabar numa construção exclusiva da noção de conflito psíquico indispensável à psicanálise.

Ao mesmo tempo, Freud, sensível a essas descobertas (os endocrinologistas arrebanham quatro prêmios Nobel em vinte anos ${ }^{8}$ ), modifica nas edições sucessivas de Drei Abhandlungen sua doutrina da libido. Ele retoma seu antigo naturalismo biologizante, e especula sobre os laços entre sexualidade e hormônios. André Tridon, num texto bastante citado, prolonga ainda mais a assimilação?. Que Freud tenha sempre mantido a au- 
tonomia da análise psicológica do desejo não detém ninguém. Com grande auxílio de encartes publicitários e de promessas ousadas (interromper a menopausa, curar a calvície), os laboratórios farmacêuticos empanturram o público norte-americano de informações semi-eruditas e de esperanças. $\mathrm{O}$ behaviorismo universitário, pós-watsoniano, por essência prudente quanto ao elo entre comportamento observável e fisiologia, desenvolve-se então num estilo insensível e hiperabstrato: ele não tem tanto a oferecer.

Todavia, é na Europa que as conseqüências das descobertas endocrinológicas para a identidade sexual vão ter a repercussão técnica mais espetacular. Um aluno de Magnus Hirschfeld, Eugen Steinach, é conhecido por ter prescrito hormônios a Freud (com um objetivo que desconheço). O mesmo Steinach, em 1912, teria já tentado, instigado por Hirschfeld, um implante de ovários num homem. É preciso dizer que a ablação dos ovários nas histéricas era uma operação muito comum antes de 1900; não havia necessariamente exagero lógico em procurar então uma simetria. Mas é seu aluno, o cirurgião Felix Abraham, quem vai primeiro operar em 1921, numa clandestinidade relativa, "Rudolf”, o primeiro transexual redefinido. O caso de Andreas Sparre, aliás Einar Weigner (aliás Lili Elbe) é mais conhecido sob o nome de Niels Hoyer, e com um prefácio do grande sexólogo britânico Norman Haine, ele contou sua experiência através de um espesso filtro de pseudônimos ${ }^{10}$.

A vaginoplastia era uma técnica bem dominada desde a segunda metade do século XIX: a faloplastia começava a sê-lo graças a Harold Gillies, um dos pais da cirurgia plástica, virtuose de sua profissão, que a havia experimentado em 1917 em soldados mutilados. Gillies, ao qual se dirigiram após 1919 os intersexuais, e que redigiu um manual de cirurgia urogenital sobre essas pacientes, opera também alguns transexuais ${ }^{11}$. Ele parece ter praticado a primeira faloplastia em Laura Dillon, que se tornou Michael, primeira militante do "direito moral" à mudança de sexo ${ }^{12}$. Ele os considera todos, como Abraham, e mesmo Daniel Stürup (que fará parte da equipe encarregada de Goerge Jorgensen em 1952) como homossexuais e transvestistas.

Como se vê, a escolha de responder à demanda de operação tal como se apresenta na boca dos pacientes é comandada no segundo plano por um feixe denso de assunções teóricas: se o estatuto hormonal rege absolutamente a vivência mental (é o fundo de representações populares e semi-eruditas sobre o qual ele se apóia), não é mais necessário interrogar a demanda enquanto tal, a prova está na convicção subjetiva do doen- 
te e sua insistência em se fazer operar. O argumento compassional é tão forte que jamais se interrogam os psiquiatras (de fato, nos anos 60, e não antes, eles se escandalizarão com as decisões tomadas sem que fossem consultados). Os doentes não são loucos, mas homossexuais infelizes (essa infelicidade explicaria sua tristeza psíquica); dispensava-se a perícia extramédica além do bom senso. E a raridade do fenômeno não permitia muito a avaliação de um verdadeiro risco deontológico.

Quanto aos sexólogos como Benjamin, ele também aluno de Steinach, sua posição militante os protegia de interrogar além da demanda explícita dos pacientes, ou o que teria podido determinar sua vivência íntima e seu sentimento de liberdade. Benjamin, tendo pedido uma psicanálise a Freud, fora recusado. Freud havia, parece, atribuído sua impotência à homossexualidade. Desde então, Benjamin se tornou um adversário feroz da psicanálise, e procurou na endocrinologia uma terapia alternativa a todos os distúrbios sexuais. A antipatia entre as duas maneiras de ver é neste caso uma questão de indivíduo para indivíduo.

Se forem aceitas algumas anedotas espetaculares da Segunda Guerra Mundial (a mais chocante foi certamente a transexualização forçada de um transvestista, num campo de concentração nazista na França), a história viva do transexualismo recomeça nos Estados Unidos. Ela coincide com o desenvolvimento de uma sociologia minuciosa, quase clínica, atenta aos "papéis" funcionais dos indivíduos e dos agentes, e que se esforça em traduzir em todos os terrenos o empreendimento abstrato de Talcott Parsons. A demonstração de interesse social da sociologia foi enorme, e os psicólogos que se ocupam dos hermafroditas vão se colocar a questão de saber se é a natureza ou a cultura quem decide a identidade sexual dos indivíduos ambíguos e encontrar os meios empíricos (estatísticas, questionários, etc.) para decidi-lo. Influenciados por Erwin Goffman, e também por Harold Garkinkel, cujo estudo do caso "Agnes” (um transexual que se fez passar por intersexual) permanece ainda um clássico da sociologia, esses pesquisadores vão retomar sob o ângulo da teoria do papel social, e não mais biológico, a assimilação tradicional do transexualismo a uma forma de "hermafroditismo psíquico".

John Money, em Johns Hopkins, domina completamente o período. Persuadido de que as crianças têm sua identidade sexual fixada irrevogavelmente por volta dos 3 anos de idade, ele vai legitimar o procedimento de redefinição sexual ainda em vigor hoje, que em caso de mutilação ou de hermafroditismo declarado, recomenda a cirurgia (castração dos machos genéticos, por exemplo) acompanhada de uma educação sem equí- 
voco no sexo feminino. Todo o saber biológico sobre o hermafroditismo humano acumulado desde os anos 20, e cuja suma é o manual de Hugh Young $^{13}$, é interpretada sociologicamente. Que a identidade sexual resulte essencialmente de uma aprendizado do "papel de gênero", e que a identidade de gênero daí resulte, não será mais colocado em questão.

É preciso dizer que as concepções psicanalíticas não encontravam muitos meios de afirmar o contrário. Mesmo o psicanalista e psiquiatra Robert Stoller, que em Stanford, com Garfinkel, vai iniciar os primeiros tratamentos de transexuais, ignora a rara clínica psicanalítica sobre o hermafroditismo. Esta solicita pois uma construção de identidade sexual pessoal extraordinariamente resistente aos eventuais desmentidos anatômicos; não é evidente, pois, que seja necessário sempre regularizar pela cirurgia os órgãos genitais dos hermafroditas. Porém, em torno desse nó doutrinal estabelecido por Money, uma multidão de trabalhos antropológicos vai se desenvolver, bem como polêmicas, como a de Julianne ImperatoMacGinley, sobre a parte da natureza e da cultura no estabelecimento da identidade, mas cada vez sistematizando as aquisições culturais (Margaret Mead, Bronislav Malinowski, Karen Horney em psicanálise). Todos eles terão como resultado consagrar definitivamente a distinção do "sexo" biológico e do "gênero" psicossocial. Cada um é o que "passa” em sua interação social, a identidade sexual não escapa à regra.

Os transexuais não fazem senão confirmá-la. A abordagem sociológica da época é, de fato, de imediato despatologisante. Não se trata para Money de aceitar o quadro sexológico e médico tradicional das parafilias, porque ele é sensível à questão do "desvio", ou seja, as regras que os indivíduos estigmatizados seguem no processo que os coloca à execração da sociedade. Não se pode pois ver nesse comportamento de transexuais condutas "anômalas", ou seja, anti-sociais, e patológicas nesse sentido, porque, ao contrário, eles administram racionalmente suas chances de inserção como seu risco de exceção. $O$ fato de eles serem adaptados, conscientes do "papel" que desempenham, e de empurrarem mesmo a cumplicidade com o sociólogo até a descrição de suas condutas em termos de "papel” e de construção identitária, confirma a intuição do início: como os hermafroditas educados num sexo social que não é seu sexo cromossômico, eles podem aliviar seu mal-estar com a ajuda do cirurgião e do endocrinólogo e interagir de modo fluído com as demais pessoas.

A difusão mundial da história de Georges Jorgensen, GI que se tornou Christine, graças a Harry Hamburger e à equipe dinamarquesa de Christian Hamburger, e que foi eleito "mulher do ano" em 1953, vai ali- 
mentar a reflexão sociológica sobre a identidade sexual e a relatividade das categorias do gênero com as situações vividas cada vez mais numerosas. A mediatização do caso logo pareceu favorecer a multiplicação vertiginosa das demandas (embora se pensasse atingir apenas uns poucos casos marginais), a ponto de suscitar as interrogações de Hamburger. De modo significativo, são os psicanalistas os mais vigorosamente colocados contra a banalização das operações, porém não em nome de convicções psicanalíticas: em nome da fraqueza de protocolos de avaliação das conseqüências, e portanto, como psiquiatras ${ }^{14}$.

De fato, esse problema é evidente: os transexuais que se dizem satisfeitos com as conseqüências das operações cirúrgicas são avaliados com critérios os mais objetivos possíveis (adaptação social medida pelo emprego, estabilidade, etc.). Não se cogitam de outros, e sobretudo não se faz a avaliação interpessoal e subjetiva que os psicanalistas reclamam. Não se considera, em particular, o fato de que o cuidado psicoterapêutico é um sucesso quando previne ou retém o transexual de se fazer operar. O fracasso de curar seu mal-estar psíquico é imputado ao psicanalista, enquanto a solução mutilante irreversível - porque faz desaparecer os motivos alegados pelo paciente de seu mal-estar - é creditada à técnica cirúrgica $^{15}$.

Mas seria este o problema correto? Que a sociedade se contente com os resultados das operações vale como solução de um problema psiquiátrico, como argumentam os adversários desses procedimentos? Que alguém se sinta "satisfeito" de passar por uma mulher, com uma neo-vagina e doses massivas de hormônios, isto é uma cura, a prova do bom efeito de um tratamento, o efeito previsível (neutro no plano médico) da satisfação de uma demanda insistente e antiga, ou a prova definitiva de que ele é louco? Tudo depende de fato dos critérios éticos implícitos (a definição da melhora) e da idéia da subjetividade que se faz (é evidente que, após a operação, as possibilidades de reelaboração pessoal da vivência transexual são reduzidas a nada), e que comandam a leitura dos resultados de pesquisa que medem a "satisfação".

Mas as respostas dos psicanalistas, quando lhes é solicitado oferecer etiologias alternativas à redução sociológica, tem sido em geral muito fracas, porque elas não conseguem acomodar o principal problema que coloca uma subcategoria precisa de transexuais (os ditos primários porque manifestam a síndrome desde a mais tenra infância e que nunca quiseram mais que, em todas as circunstâncias, repudiar seu sexo): a ausência de conflito psíquico patente, e a tranqüila segurança de que seu proble- 
ma é social (como fazer os outros aceitarem uma evidência?) e não men$\mathrm{ta}^{16}$. Mesmo Stoller, o mais informado dos primeiros teóricos psicanalistas do transexualismo, ao se esforçar em dar uma significação psicanalítica à noção de "gênero" segundo as mesmas linhas que Money (comparando transexuais, hermafroditas, crianças com órgãos genitais mutilados, etc.), precisou construir uma doutrina da qual não cessa de assinalar o caráter herético para um freudiano, porque ela parte da ausência de conflito intrapsíquico nos transexuais.

Mas como ele insiste na impossibilidade de objetivar a clínica que lhe permite sustentá-la, e seus dados são muitas vezes indiretos, ou casuais como toda psicanálise, jamais seu trabalho, apesar de sua prudência e de seu bom senso, pode inquietar o paradigma dominante da "satisfação” dos transexuais operados. No limite, ao fazer concessões maiores aos saberes extrapsicanalíticos, e usando noções tão problemáticas como o imprinting dos amamentados por suas mães, como Lorenz, ou como a teoria da aprendizagem social, Stoller antes assinou a sentença de morte da autoridade da psicanálise nesse domínio: cada uma dessas explicações pode ser substituída por todas as outras que são encontradas em Freud (Édipo, recalque, etc.), e nenhuma tem necessidade de se enraizar no inconsciente.

Esses debates científicos ocorriam enquanto o número sempre crescente de demandas de redefinição sexual e a mediatização dos relatos autobiográficos de "mudança de sexo"17 faziam passar o transexualismo numa outra dimensão. Muito rapidamente, nos países onde a castração por um médico caía sob o golpe da lei (a Dinamarca era então a exceção), o problema médico-legal se colocava. É somente a partir dos anos 80 que as legislações, por toda a Europa, enquadrarão a modificação do estado civil. O único caso francês anterior é o de Jacques Dufresnoy, operado por Georges Burou em 1958 em Casablanca, e conhecido pelo nome de "Coccinelle”, que obtém o direito de se casar com o nome de Jacqueline; foi um tal escândalo que nenhum outro pedido de retificação foi aceito antes dos anos 70 .

No estado atual, as legislações exigem a medicalização da redefinição de sexo para evitar que o estado civil se torne matéria de conveniência pessoal. É preciso que as operações se inscrevam num projeto terapêutico que o magistrado leva a seu termo. O híbrido psiquiátrico-sociológico forjado com essa finalidade foi a "disforia de gênero", levada aos fundos batismais por Norman Fisk em 1973, precisamente para responder a tais necessidades funcionais, e sem nenhuma ambição nosográfica ${ }^{18}$. Ela replicava pala- 
vra por palavra à demanda dos transexuais, transportando seu autodiagnóstico (não se sentir do sexo adequado) para a definição médica da síndrome, e consagrava no mesmo movimento como única escolha terapêutica aquela que eles solicitam (hormônios e cirurgia). É o reconhecimento de um ato de transformação concebido como um ato livre, mas formulado em termos que permitem ainda descrevê-lo como uma síndrome, e portanto preservar uma zona de especialidade médica (é preciso verificar se os pacientes não são esquizofrênicos); o problema é que a anormalidade sintomática do transexualismo não se mede mais a partir daí senão pela inadequação social ressentida, em lugar de uma norma da saúde mental. Os avatares da disforia de gênero abriram em seguida um caminho nas nosografias oficiais (as versões sucessivas do DSM), no quadro global dos "distúrbios da identidade de gênero”.

É precisamente a exigência terapêutica que constitui hoje a última fronteira do transexualismo. Desde o momento em que a disforia de gênero não tem de médico senão o fato contingente de ser repertoriada entre as síndromes psiquiátricas, não existe mais razão em conservá-la que conservar a homossexualidade entre as doenças mentais. De resto, foi também em 1973 que com base em um voto (era impossível atingir um con90 senso entre psiquiatras sobre as bases científicas) a Associação Psiquiátrica americana retirou a homossexualidade da lista das patologias; a decisão surtirá efeito na DSM 3, em 1980. Nessa fase, à qual nós pertencemos, a instrumentalização consciente e deliberada da cirurgia e dos hormônios aos fins do desabrochar individual, a escolha do estilo de vida sexual no contexto geral da emancipação dos costumes, e conjuntamente, a crítica erudita da normatividade dimórfica veiculada pelo feminismo militante, são os grandes pontos de referência.

É tempo de os "transgender" ou transexuais, transvestistas, homossexuais de apresentação voluntariamente ambígua, mas também certos hermafroditas, empreenderem uma desconstrução lúdica mas também politicamente armada dos estereótipos sexuais onde se aliena o desejo. Parece que o primeiro a utilizar o termo transgender para designar uma forma de coalizão contestatória dos inimigos dos estereótipos sexuais foi um transvestista militante, Charles Prince (que se tornou Virginia) ${ }^{19}$. Utilizando os hormônios para feminilizar sua aparência, mas recusando a emasculação cirúrgica, Prince tornou-se um dos principais especialistas das práticas transvestistas.

Dois elementos essenciais emergem aqui. O primeiro é o conflito aberto que opõe os defensores de um transexualismo "assimilacionista", 
em que o alvo seria fundir-se num sexo visado, sendo o transexual uma pura transição, e os transgeneristas, para quem a refutação ativa dos estereótipos sexuais é um fim subversivo em si mesmo, e que recusam reconstituí-los “do outro lado” sob uma forma inversa. Janice Raymond, em uma obra controversa, The Transsexual Empire ${ }^{20}$, acusou os transexuais feminilizados de distorcer o movimento feminista com fins tipicamente masculinos, e de encorajar o endurecimento dos estereótipos sexuais opressores.

No entanto, foi a militância feminista e homossexual que ofereceu o modelo às organizações transexuais (e transgeneristas) da segunda geração, cuja ambição não é mais fornecer o acesso à redefinição sexual aos indivíduos isolados e desprovidos de informação, mas sim lutar contra a discriminação econômica, ou policial, etc. ${ }^{21}$ Os tumultos do Stonewall bar, em Brooklin, em junho de 1969, que opuseram durante muitos dias seguidos os homossexuais à polícia, são o evento fundador dessa militância; muitas vezes se esquece que elas foram de início o resultado de uma mobilização de transvestistas e de transexuais, vítimas de uma homofobia mais ampla, mas da qual eles eram os alvos mais facilmente identificáveis. De subcultura semiclandestina, destinada a fazer circular as "artimanhas" às quais os médicos detentores do poder de operar eram reputados sensíveis (histórias de vida típicas, práticas de dissimulação, etc), o transgenerismo tornou-se pouco a pouco um movimento libertário com vastas ramificações, notadamente acadêmicas e literárias, que se alimenta da tradição associativa e comunitarista americana, e utiliza a Internet do mesmo modo que os protestos pelos direitos cívicos dos anos 60. Um dos prolongamentos mais interessantes é o movimento de protesto que se organizou contra a redefinição cirúrgica dos intersexuais, mutilados para satisfazer os estereótipos conformistas do gênero ${ }^{22}$. Ora, os antigos argumentos psicanalíticos não são invocados aqui: pelo contrário, o transgenerismo, com sua contestação sociológica do dimorfismo sexual, parece fornecer o essencial dos argumentos.

Todavia, fora dos Estados Unidos essa versão do transgenerismo permanece marginal. Nos Países Baixos, onde a tradição liberal em bioética é notória, na Universidade Livre de Amsterdã foi criada em 1990, pelo endocrinologista Louis Gooren, a primeira cátedra especializada. Ali se formou o centro de uma atividade mais tradicional, orientada para o transexualismo, e para quem o transgenerismo é sobretudo um derivado cultural e político. Nessa instituição, os trabalhos sobre o hipotálamo dos transexuais, diretamente deduzidos dos de Simon LeVay ${ }^{23}$, servem de re- 
ferência ${ }^{24}$. E a Corte Européia dos Direitos do Homem (CEDH) em Strasbourg, da qual um dos membros era transexual, solicitada regularmente por pacientes operados que se sentem discriminados (pelo casamento, adoção, etc.), prefere ainda a interpretação médica da síndrome à sua interpretação cultural.

Apesar dos conflitos de superfície, é no entanto patente que a abordagem sociológica e a procura de um embasamento neuroendócrino não são contraditórias: já é escolarmente trivial afastar as oposições nature$\mathrm{za} /$ cultura, exacerbadas no caso do transexualismo, em nome de sua complementaridade. Em troca, se um estrito determinismo se exerce sobre os sujeitos, se seu sexo psicossocial não está em seu poder mais que o fato de ser de direita ou de esquerda, então está aberta para eles a porta do reconhecimento jurídico de seu estatuto e das adaptações devidas a uma minoria sexual reprimida. É nesta direção que caminham hoje as organizações de transexuais, mas elas não obtêm mais que as medidas de proteção decorrentes do direito fundamental da não-intervenção do Estado na esfera privada (no sentido da privacy anglo-saxônica). Daí em diante, as duas concepções do transexualismo não se encontram de maneira alguma: a psicanalítica, que continua a manter - pela evocação de uma clínica cada vez mais precisa - o caráter patológico e com freqüência delirante da esperança de mudar de $\operatorname{sexo}^{25}$, e a do militantismo transgender, na ponta da luta pelo reconhecimento legal. Há muitas evidências de que os psicanalistas querem de fato defender a existência de uma psiquiatria que mensuraria os distúrbios mentais com uma outra norma que a aceitabilidade social dos desvios, enquanto os militantes transgender denunciam na psicanálise um dogmatismo desprovido de bases científicas que legitime $a$ posteriori os preconceitos conservadores. Tais anátemas recíprocos refletem uma dificuldade exemplar de nossas concepções antropológicas: estão em luta as que trazem uma visão do homem como indivíduo livre, transparente para si mesmo, instrumentalizando a ciência para realizar um projeto do qual ele é o único responsável e que se mede pelos ideais hedonistas; e aquelas que vêem na transparência pretendida a consciência de uma ilusão radical, nas quais a sexualidade e a identidade sexual não-escolhidas são as pedras de toque, com uma desconfiança pela técnica médica que refabricaria o humano. Como essas duas opções são opções morais, seria muito arriscado considerar que uma ou outra possa ser definitivamente vencida (ao menos no círculo historicamente definido de nossa cultura e de nossa sociedade). 
CRONOLOGIA E BIBLIOGRAFIA DO TRANSEXUALISMO E DAS PATOLOGIAS CONEXAS DA IDENTIDADE SEXUAL NA FRANÇA, NA EUROPA E NOS

ESTADOS UNIDOS, EM PSIQUIATRIA, PSICANÁLISE, SEXOLOGIA, ENDOCRINOLOGIA E CIRURGIA (COM OS PRINCIPAIS EVENTOS INSTITUCIONAIS E OS TEXTOS SOCIOLÓGICOS, JURÍDICOS, LITERÁRIOS OU CRÍTICOS RELACIONADOS), DE 1910 A $1995 .{ }^{26}$

1910 HIRSCHFELD, Magnus. Die Tranvestiten. Eine Untersuchung über den erotischen Verkleidungstrieb mit umfangreich casuistichem und bistorischem Material. Berlin: Pulvermacher e Leipzig: Spohr. Primeiro uso do termo "transexualpsíquico".

1911 Morte de Daniel Paul-Schreber. FREUD, Sigmund.Psychoanalytische Bemerkungen über eine autobiographisch beschrieben Fall von Paranoia (Dementia Paranoides). Jarbuch für Psychoanalytische und Psychopathologische Forschung n.o 3-1, pp. 9-68.

1912 Magnus Hirschfeld, que sugeriu a Eugen Steinach suas experiências sobre as glândulas endócrinas, menciona uma primeira intervenção cirúrgica e hormonal de redefinição sexual.

1914 HIRSCHFELD, M. Die Homosexualität des Mannes und des Weibes. Berlin: Louis Marcus.

1917 Harold Gillies, cirurgião britânico, pratica durante a guerra as primeiras faloplastias.

1918 Magnus Hirschfeld funda em Berlin o Institut für Sexualwissenschaft

1921 Operação de "Rudolf” em Dresde, por Felix Abraham, aluno de Magnus Hirschfeld, que reopeera duas vezes o paciente para dar-lhe uma aparência feminina em 1930: primeiro caso de transexualismo masculino tratado pela cirurgia.

1922 Publicação dos trabalhos de Wilhelm Stekel sobre as aberrações sexuais, que introduz o termo "parafilia" para substituir o de perversão.

1923 Início dos trabalhos de W.M. Allen e Edward Doisy, na Universidade de Saint-Louis, sobre os hormônios femininos. A nova endocrinologia começa a servir de caução científica na polêmica contra a psicanálise: discussão por TRIDON, A. Psychoanalysis and Gland Personalities. New York: Brentano. Albert Moll completa a Psychopathia sexualis de Richard Krafft-Ebing e especialmente a observação no ${ }^{-129}$, caso-tipo do transexualismo masculino. GOLDSCHMITH, R. The Mechanism and Physiology of Sex Differentiation. Tradução do inglês de William Dakin. London:Methuen. Referência principal sobre a "intersexualidade" (nascimento do termo) na nova endocrinologia alemã. 
1924 Descrição por Hugh Young do primeiro caso de hermafroditismo lateral.

1928 WOOLF, Virginia. Orlando. New York: Harcourt Brace.BERMAN, L.The Glands Regulating Personality. New York: Mac Millan. Obra clássica do behaviorismo endocrinológico (reeditado em 1935).

1929 FRANK, R. The Female Sex Hormone. Springfield: Charles Thomas. Obra que vulgarizou os estrógenos.

1930 Einar Wegener ("Lili Elbe”) pede a Magnus Hirschfeld para transformá-lo em mulher. Felix Abraham pratica algumas vaginoplastias (uma técnica então bem dominada) e implantações de ovários. Harry Benjamin reencontra Freud (que se recusa a analisá-lo). FAIRBAIRN, W. R. D.," Features in the analysis of a patient with a physical genital abnormality", Psychoanalytic Studies of the Personality. London: Routledge \& Kegan, 1981. Um dos raríssimos casos de análise de paciente intersexual.

FENICHEL, O. The psychology of tranvestis". International Journal of Psychoanalysis, n. 11, pp. 211-227.

1931 Adolph Friedrich Johann Butenandt, de Göttingen, isola e cristaliza a androsterona já caracterizada por McGee. Despenalização das castrações terapêuticas na Dinamarca. ABRAHAM, Felix. Genitalumwandlung na Zwei maennliche Trans vestte, Zeitschrift für Sexualwissenschaft, n. 18, pp. 223-226.

HIRSCHFELD, M. Perversions sexuelles. Paris: François Aldor (ed. de Felix Abraham).

1932 Conferência em Londres, dita de " padronização dos hormônios sexuais”, à qual o francês A. Girar leva $20 \mathrm{~g}$ de estrógeno (foliculina).

1933 Fechamento do Institut für Sexualwissenschaft de Berlim.HOYER, N. Man into woman: na authentic Record of a Change of Sex. Trad. e prefácio de Norman Haine. London: Jarrolds; New York: Dutton. Relato da vida de Einer Wegener (nascido Andreas Sparre) por Ernst Ludwig Harthern Jacobsen, sob o pseudônimo de Niels Hoyer.

1934 Leopold Ruzicka, na Suíça, sintetiza pela primeira vez a androsterona a partir do colesterol. Adolph Friedrich Johann Butenandt, na Alemanha, O. P. Winterstein e W.M. Allen nos Estados Unidos isolam e cristalizam a progesterona do corpo amarelo. ROBINSON, W. Our Mysterious Life Glands. How They Affect Us. New York: Eugenics Publishing. Texto-guia da endocrinologia popular.

1935 Morte de Magnus Hirschfeld K. David, E. Dingemanse, J. Freud e E. Laqueur isolam a testosterona. E. Doisy descobre o estradiol (dihydrofoliculina). HILL, W.W., The status of the hermaphrodite and transvestite in Navaho Culture, American Anthropologist, n. 37, pp. 273-279. 
1936 Síntese do estradiol (ethynil-estradiol), que servirá para a produção das primeiras pílulas anticoncepcionais e das primeiras autoministrações de hormônios para os transexuais. ELLIS, H. Studies in the Psycho$\log y$ of Sex. I, "Sexual Inversion”, e II “Eonism”. New York: Random House. FAIRBAIRN, W.R.D. The effect of a king's death upon patients undergoing psychoanalysis. Psychoanalytic Studies of the Personality. London: Routledge \& Kegan, 1981. Seguida da análise da paciente de 1931. HIRSCHFELD, M. Le sexe inconnu. Paris: Montaigne.

1937 DEVEREUX, G. Institutionalized homosexuality of the Mohave indians. Human Biology, no 9, pp. 502-527. YOUNG, H. Genital Abnormalities. Hermaphroditism and Related Adrenal Disorders. Baltimore: Williams and Wilkins. É o grande manual sobre o hermafroditismo.

1938 Primeiro encontro de Daniel Stürup com um transexual, que ele considera um homossexual em sofrimento que solicita ser castrado.

1939 Adolf Friedrich Johann Butenandt e Leopold Ruzicka recebem o prêmio Nobel de química por seus trabalhos sobre os esteróides sexuais.

1942 FINESINGER, J., MEIGS, J. e SULKOWITCH, H. Clinical, psychiatric and psychoanalytic study of a case of male pseudohermaphroditism. American Journal of Obstetrics and Gynecology, n. 44, pp. 31-37.

1943 Edward Doisy recebe o prêmio Nobel de medicina por seus trabalhos de endocrinologia. Georges Marie André Schwidenhammer, preso pela Gestapo, é internado em Struthof e sofre tratamentos hormonais feminilizantes. Ao ser libertado, é o primeiro a solicitar mudança de estado civil, que obtém em 1975.

1944 GUTERNATSCH, F. True hermaphroditism: Concerning the 37 cases reported. Journal of Urology, n. 52, p. 621.

1945 DE KRUIF, P. The Male Hormone. New York: Harcourt Brace. Esta obra populariza a testosterona.

1946 DILLON, M. Self: A study in Ethics and Endocrinology. London: Heinemann. O primeiro texto a defender a retificação pela medicina do "erro da natureza" (atribuído a uma desordem endócrina) no hermafroditismo e no transexualismo. A ênfase é colocada sobre a liberdade de escolha. O livro foi escrito antes da transformação de Laura em Michel (por meio de testosterona e de uma faloplastia por Harold Gillies).WOLFF, E. Les changements de sexe. Paris: Gallimard. Manipulações sobre o embrião que colocaram em evidência, a função dominante dos alossomas XY e o papel dos hormônios na sexuação dos organismos em gestação.

1947 COTTE, G. Plastic operations for sexual ambiguities (gynandrines e androgynes). Journal of the Mount Sinaï Hospital, no 14, pp. 171-174. 
Os dilemas cirúrgicos e o peso do papel psicosocial na escolha do sexo em casos duvidosos, pelo melhor especialista francês.

1949 CAULDWELL, D. Psychopathia transexualis. Sexology, n. 16, pp. 274-280. Sobre um caso de transexual (“Earl”) que queria se masculinizar.

1952 Operação de George/Christine Jorgensen em Copenhague pela equipe de Christian Hamburger, constituída pelo psiquiatra Daniel Stürup e os cirurgiões Poul Fogh-Andersen e Erling Dahl-Iversen (sem vaginoplastia).

1953 Georges Burou começa a operar transexuais em Casablanca. BENJAMIN, H. Transvestism and Transsexualism. International Journal of Sexology, n. 7, pp. 12-13. Ataque violento contra todo tratamento psicoterapêutico e sobretudo psicanalítico do transexualismo e do transvestismo. HAMBURGER, C., STÜRUP, D e DAHL-IVERSEN, E. Transvestism: Hormonal psychiatric and surgical treatment. Journal of the American Medical Association, n. 152, pp. 391-396. O caso Jorgensen, qualificado de "eonismo", como em Ellis. HAMBURGER, C. The desire for change of sex as shown by personal letters from 465 men and women. Acta Endocrinologica, n. 14, pp. 361-375. OSTOW, M.K. Letter to the Editor. Journal of the American Medical Association, n. 152, p. 1553. Protesto contra a operação de Jorgensen.

1954 Christine Jorgensen é eleito "mulher do ano". COWELL, R. Roberta Cowell's story. New York: British Book Centre. Tradução francesa em 1955: Comment je suis devenu femme. BENJAMIN, H. Transvestism and transsexualism as psycho-somatic and somatopsychic syndromes. American Journal of Psychotherapy, n. 8 (consagrado a um simpósio sobre transexualismo e transvestismo). GUTHEIL, E. The psychoanalytic background of transsexualism and transvestism.American Journal of Psychotherapy, $\mathrm{n}^{\mathrm{o}} 8$. Artigo fundador da teoria psicanalítica do transexualismo por um conflito nevrótico.

1955 Primeira menção do conceito de "gênero" por John Money, após a idéia do "papel" aplicado à diferença dos sexos por Talcott Parsons. Hedy Jo Star, nascido Carl Rollins HAMONDS (I Changed My Sex) se torna célebre na esteira da operação de George Jorgensen. MONEY, J., HAMPSON, John e HAMPSON, Joan. Hermaphroditism: recommendations concerning assignment of sex, change of sex, and psychological management. Bulletin of the Johns Hopkins Hospital, n. 97, pp. 301-319. Ponto de partida de práticas de redefinição para os intersexuais. IDEM. An examination of some basic sexual concepts: the evidence of human hermaphroditism. Bulletin of the Johns Hopkins Hospital, $\mathrm{n}^{-}$97. Estudo de pares de hermafroditas educados 
em gêneros diferentes, concluindo pela neutralidade psicossexual no nascimento. WORDEN, F.G. e MARSH, J.T. Psychological factors in men seeking sex transformation. Journal of the American Medical Association, n. 157, pp. 1.291-1.298. Primeiro estudo científico geral sobre o transexualismo de um ponto de vista psicológico.

1956 ALBY, Jean-Marc. Contribution à l'étude du transsexualisme. Thèse de médecine, Paris. CAULDWELL, D. (ed.). Transvestism. Men in Female Dress. New York: Sexology Corporation. LINDON, R. Aspects juridiques du transexualisme. Recueil général des lois, no 95.

MONEY, J., HAMPSON, John e HAMPSON, Joan. Sexual incongruities and psyhopathology: the evidence of human hermaphroditism. Bulletin of the Johns Hopkins Hospital, no 98, pp. 43-57.

1957 GILLIES, H. e MILLARD, R. Principles and Art of Plastic Surgery. Boston: Little and Brown; London: Butterworth. Estudo técnico das operações de redefinição. MONEY, J. HAMPSON, John e HAMPSON, Joan. Imprinting and the stablishment of gender role. Archives for Neurology and Psychiatry, n. 77, pp. 333-336. Teoria neo-etiológica do transexualismo, como em Lorenz (que exclui o conflito intrapsíquico).

1958 Agnes apresenta-se a Robert Stoller, Harold Garfinkel e Alexander Rosen, na Universidade de Califórnia, Los Angeles, como hermafrodita, para uma cirurgia corretiva; diagnóstico de síndrome testicular feminisante. DELCOURT, M. Hermaphrodite. Paris: PUF. DE SAVITSCH, E. Homosexuality, Transvestism and change of Sex. Springfield: Carles Thomas.

1959 GOFFMAN, E. The presentation of Self in Everyday Life. New York: Doubleday. Obra que constitui referência para a análise social do papel de gênero.

1960 STOLLER, R., GARFINKEL, H e ROSEN, A. Passing and the maintenance of sexual identification in a intersexed patient. Archives of $G e$ neral Psychiatry, $\mathrm{n}^{\circ}$ 2, pp. 379-380. Encontro com Agnes.

1961 OVERSIER, C. Intersexuality. London: Academic Press. Referência, notadamente, para as normas cirúrgicas discutidas por Heinz Gelbke.

1962 A nova edição do Oxford English Dictionary afirma que "sexo" e "gênero" não são mais equivalentes, mas que "gênero" acentua a dimensão social e cultural, por oposição à definição biológica. Jacqueline-Charlotte Dufresnoy (nascido Jacques), aliás "Coccinelle”, operada em 1958 em Casablanca, obtém mudança de seu estado civil, e se casa: escândalo nos meios judiciários que rejeitam toda nova solicitação. SMOLKA, H. Die Indika0tionsstellung zur Anlegung einer hünstlichen Scheide bei Aplasia vaginae aus psychologischer una soziologischer Sicht. Geburtsh und Frauenheilkunde, n$^{\circ}$ 22, p. 1.187 . 
1964 Criação da Erickson Educational Foundation por Reed Erickson, em Baton Rouge, Louisiana, para estudo do transexualismo. Ela começa a subvencionar os projetos da futura Harry Benjamin Association. EDGERTON, R.B. Pokot intersexuality: na East African example of the resolution of sexual incongruity. American Anthropologist, n. 66, pp. 12881299. SPERLING, M. The analysis of a boy with transvestite tendencies. The Psychoanalytic Study of the Child, no 19, pp. 470-493. STOLLER, R. A contribution to the study of gender. International Journal of Psychoanalysis, $\mathrm{n}$. 45 , pp. 220-226. Caso de uma menina que afirma ser na realidade um macho biológico, e introdução do conceito de "identidade de gênero". Publicação de The hermaphrodictic identity of hermaphrodites, Journal of Nervous and Mental Diseases, ํㅡㄴ 139-145, pp. 453-457.

1965 Primeira operação de "conversão sexual” praticada nos Estados Unidos na clínica de Johns Hopkins, determinada por um tribunal de Baltimore.

1966 M. Delcourt publica Hermaphroditas, em Bruxelas, complemento iconográfico de seu livro de 1956. BENJAMIN, H. The Transsexual Phenomenon. New York: Julian Press. Define o transexual pela solicitação de redefinição cirúrgica. GREENSON, R.R. A transvestite boy and a hypothesis. International Journal of Psychoanalysis, n. 47, pp. 396-403.

1967 O Sexual Offence Act britânico permite indiretamente operar os transexuais, o que começa a ser feito no Charing Cross Hospital com o cirurgião Phillip e o psiquiatra John Randell. A federação internacional de atletismo amador impõe controles do sexo cromossômico aos atletas. JORGENSEN, C. A personal Autobiography. Forest Dale: Paul Ericksson. Prefácio de H. Benjamin. GARFINKEL, H. Studies in Etbnometodology. Englewoods Cliffs: Prentice-Hall. Cinco capítulos são consagrados a Agnes. WALINDER, J. Transsexualism: A Study of Forty-three Cases. Trad. de Helen Fry. Stockholm: Scandinavian University Books.

1968 O CIO, nos jogos do México, institui um teste de cromatina para verificar o sexo dos atletas. Lançamento do programa de pesquisas sobre gênero em Stanford (UCLA em Palo Alto). Gore Vidal publica Myra Breckinridge, que será filmada em 1970 por Michael Sarne. STOLLER, R. Sex and Gender: On the Development of Masculinity and Feminity. New York: Science House; London: Maresfield. Trad. francesa como Recherches sur l'identité sexuelle. Paris: Gallimard, 1978. Introdução do conceito de "core gender identity”. KUBIE, L.S. e MACKIE, J.B. Critical issues raised by operations for gender transmutation. Journal of Nervous and Mental Diseases, n. 147, pp. 331-343.

1969 Primeiro congresso, em Londres, da Harry Benjamin Associa- 
tion. Distúrbios de Stonewall, em junho, em New York, contra os vexames policiais anti-homossexuais; início do militantismo gay. ACCARD, J.; BRETON, J.; CHARBAUT, J.; HIVERT, P.; PHILBERT, M.; SCHAUB, S.; TROISIER, S. Problèmes médico-legaux et déontologiques de l'hermaphrodissme et du transsexualisme. XXXIIIème Congrès de médecine légale et de médecine sociale de langue française, Gênova. GREEN, R. e MONEY, J. (ed.). Transsexualism and Sex Reassignment. Baltimore: Johns Hopkins University Press. SOCARIDES, C. The desire for sexual transformation. A psychiatric evaluation of transsexualism. American Journal of Psychiatry, n. 125, pp. 125-131. STOLLER, R. A biased view of "sex transformation" operations (Editorial ). Journal of Nervous and Mental Diseases, n. 149 , pp. 312-317.

1970 Caso Corbett versus Corbett (dito Ashley), que fixa a jurisprudência inglesa sobre o sexo com base no sexo cromossômico (All England Law Report, n. 2, pp. 32-51). SOCARIDES, C. A psychoanalytic study of the desire for sexual transformation ("transsexualism"). American Journal of Psychoanalysis, n. 51, pp. 341-349. KREISLER, L. Les intersexuels avec ambiguïté génitale. La psychiatrie de l'enfant, no 13-1, pp. 5-127. Excelente análise psicológica, que contradiz bastante John Money; enriquecida de 114 referências bibliográficas. ZUGER, B. Gender role determination. A critical review of the evidence from hermaphroditism. Psychosomatic Medicine, n. 32-5, pp. 449-467.

1971 II Congresso da Harry Benjamin Association em Copenhague. Léon Pérel pratica em uma estudante de medicina a primeira operação de redefinição sexual na França, no hospital Saint-François em Paris. J.M. Saez isola uma nova classe de hermafroditismo por déficit en 17-betahydrosystéroido-deshydrogenase. Fundação por Richard Green dos Archives for Sexual Behavior. GREEN, R. e STOLLER, R. Two monozygotic (identical) twin pairs discordant for gender identity. Archives of Sexual Behavior, n. 1, pp. 321-327. MONEY, J. Clinical aspects of prenatal steroidal action on sexually dimorphic behavior. In: SAWER, C. e GORSKI, R. (ed.). Steroid Hormones and Brain Functions. Los Angeles:University of California Press. DE VAAL, O. M. Man of Vrouw? Delemna van de Transsexuele Mens. Amsterdam: Wetenschappelijke Uitgeverij. Manifesto do psiquiatra holandês que iniciou a tradição liberal nos Países Baixos.

1972 Tratamento gratuito para os transexuais nos Países Baixos. Lei sobre a mudança de sexo na Suécia. O belga Daniel van Oosterwyck é o primeiro transexual europeu a passar por uma operação completa de masculinização no Charing Cross Hospital de Londres. Dörner, Rohde e Krell formulam a hipótese famosa de uma etiologia da homossexualidade por 
déficit pré-natal de andrógeno, quando da diferenciação sexual do hipotálamo.OAKLEY, A. Sex, Gender and Society. New York, Harper Colophon. MONEY, J. e EHRHARDT, A. Man and Woman, Boy and Girl: The Differentiation and Dimorphism of Gender identity from Conception to Maturity. Baltimore: Johns Hopkins University Press. Grande vulgarização da oposição "sexo/gênero". PRINCE, Virginia (nascido Charles) e BENTLER, P. Survey of 504 cases of transvestism. Psychological Reports, n. 31-3, pp. 903-917.

1973 III Congresso da Harry Benjamin Association em Dubrovnik. A American Psychiatric Association, após um grande conflito, decide por um voto sem discussão científica retirar a homossexualidade do rol das patologias listadas em DSM 3. John Money cria o conceito de "disforia de gênero”, com Norman Fisk e o cirurgião plástico Donald Laub. FISK, N. The how, what and why of a disease. In: LAUB, D. e GANDY, P. (ed.). Proceedings of the second interdisciplinary symposium on gender dysphoria syndrome. Palo Alto: Stanford University Medical Center. KANDO, T. Sex Change: The Achievement of Gender Identity Among Feminized Transsexuals. Springfield: Charles Thomas. Documenta a hiperfeminilidade visada pelos pacientes. MONEY, J. Prenatal hormones and postnatal socialization in gender identity differentiation. Nebraska Symposium on Motivation. Primeira publicação sobre o caso John/Joan. PONTALIS, J-B. (ed.). Bisexualité et différence des sexes. Número thematique de la Nouvelle revue de Psychanalyse. Paris: Gallimard. Textos importantes de R. Stoller, Faits et hypothèses: Un examen du concept freudien de bisexualité" (In Schreber, tradução de "Facts and Facies: An examination of Freud's concept of bissexuality"; in STROUSE, Women and Analysis. New York: Grossman); de A. Green, Le genre neutre (com o relato de seu encontro com Georges Marie André Schwidenhammer); de L. Kreisler sobre os intersexuais operados em SaintVincent-de-Paul em Paris. STOLLER, R. Splitting. New York: Quadrangle e The male transsexual as "experiment", International Journal of Psychoanalysis, n. 54, pp. 217-227.

1974 Publicação do best-seller de Jan Morris, Conundrum, New York: Harcourt Brace Jovanovich. Tradução francesa do mesmo ano, L'énigme. D'un sexe à l'autre. Paris: Gallimard. BEM, S.L. The Measurement of Psychological Androgyny. Journal of Consulting and Clinical Psychology, n. 42, pp. 155-162. Primeira escala de variação dos traços sexuais em psicologia. GREEN, R. Sexual Identity Conflicts in Children and Adults. New York: Basic Books. NORMAN, F. Gender Dysphoria Syndrome. The conceptualization that liberalizes indications for gender reorientation and implies a broadly bases multidimensional rehabilitative regimen. Western Journal of Medecine, n. 120, pp. 386-391. Elimina a questão do diagnóstico diferen- 
cial e abre o tratamento cirúrgico e hormonal a uma classe mais vasta de comportamentos e de vivências sexuais subjetivas. PERSON, E. e OVESEY, L. The transsexual syndrome in Males. I Primary transsexualism, II. Secondary transsexualism. American Journal of Psychotherapy, n. 28, pp. 420 e 174-193. SAFOUAN, M. Études sur l'Oedipe. Paris, Seuil. Discute o caso de Stoller.

1975 IV Congresso da Harry Benjamin Association en Stanford. Lançamento do estudo de catamnésia de Richard Green sobre 44 rapazes efeminados (nenhum se declara transexual, a metade evolui para a homossexualidade). A Corte de cassação interdita as mudanças de estado civil por causa de transexualismo. VAN OOSTERWYCK, D. Il. Bruxelles: Rossel. Testemunho do personagem central do debate jurídico na Europa. RUBIN, G. The traffic in women. Note on the political economy of sex. In: RAYNA, R. (ed.). Toward an Anthropology of Women. Texto fundador da crítica marxista feminista. BULLOUGH, V. Transsexualism in History. Archives for Sexual Behavior, n. 4, pp. 561-571. MONEY, J. e TUCKER, P. Social Signatures. Boston: Little \& Brown. Vulgarização das teses do livro de J. Money e A. Erhardt, de 1972. DAVID, C. La bissexualité psychique. Eléments d'une réevaluation. Revue française de psychanalyse, n. 39, 56, pp. 695-856. HAYNAL, A. Identité sexuelle et transsexualisme. In: ABRAHAM, G. e PASINI, W. Introduction à la sexologie médicale. Paris: Payot. MONEY, J. Ablatio Penis: Normal male infant sex-reassigned as a girl, Archives of Sexual Behavior, n. 4, pp. 65-71. Trata do famoso caso John/Joan. STOLLER, R. Sex and Gender II: The transsexual experiment. London: Hogarth Press.

1976 Um suplemento do Journal of American Psychoanalytic Association (n. 24) é consagrado ao problema do gênero e do sexo. Criação do Centre du Christ Libérateur à Paris por Joseph Doucé. FOUCAULT, M. Histoire de la sexualité I: La volonté de savoir. Paris: Gallimard. PRINCE (Virgínia, nascido Charles) publica Understanding Cross-Dressing. STÜRUP, D. Male transsexuals. A long-term follow-up after sex reassignment operations. Acta psychiatrica scandinavica, n. 53, pp. 51-63.

1977 V Congresso (fundador) em San Diego, da Harry Benjamin Association, como Harry Benjamin International Gender Dysphoria Association (HBIGDA). O tribunal de Dijon admite as operações "com finalidade terapêutica". WITHERSPOON, G. Language and Art in the Navajo Universe. Ann Arbor: University of Michigan Press. Livro crucial, mas negligenciado, para a compreensão dos conceitos da filosofia popular dos índios navajo, muito solicitada desde Georges Devereux para a reflexão sobre a distinção sexo/gênero. MARTINO, Mario (nascida Marie) e HAR- 
RIET. Emergence: A Transsexual Biography. New York: Crown Publishers. Tradução francesa em 1981, Emergence. Autobiograpbie d'un transsexuel.Paris: Trévise. CONN, C. Canary: The Story of a Transsexual. New York: Bentam. MONEY, J. e MUSAPH, H. (ed.).Handbook of Sexology. Elsevier. HAUSER, G. e SCHMID-THANNWALD, I. Im Zweifelsfall: weiblich: Vorgehen bei unklarem äuberen Genitale des Neugeborenen. Sexualmedizin, n. 6, pp. 653-661.

1978 O tribunal de Saint-Etienne admite o primeiro pedido de mudança de estado civil desde o caso Dufresnoy em 1962. FOUCAULT, M. Herculine Barbin dite Alexina B. Paris: Gallimard. HUNT, N. Mirror Image. New York: Holt, Rinehart and Winston. Trata-se da autobiografia do caso. KESSLER0, S. e McKENNA, W. Gender: An Ethnomethodological Approach. New York: John Wiley. Filia-se ao estudo de Agnes por Harold Garfinkel. GREEN, R. Sexual Identity of 37 children raised by homosexual and transsexual parents. American Journal of Psychiatry, n. 135, pp. 692-697. OH$\mathrm{NO}, \mathrm{S}$. The role of H-Y antigen in primary sex determination. Journal of the American Medical Association, n. 239, pp. 217-220. Início da controvérsia sobre o antígeno H-Y. PRINCE, Virgínia (nascido Charles). Transsexuals and pseudo-transsexuals. Archives of Sexual Behavior, n. 7, pp. 263-272.

1979 VI Congresso da Harry Benjamin Association em San Diego. Definição dos "Standards of care". Estima-se o número de transexuais hormonizados e operados entre 3 e 6000 nos Estados Unidos (entre 30 e 60000 candidatos). Primeira mudança de estado civil em Créteil motivada pela discordância entre o "sexo cerebral e psicossocial" e o sexo de nascimento. Pierre Banzet começa a operar no hospital Saint Louis em Paris. RAYMOND, J. The Transsexual Empire: The Making of the She-Male. Boston: Beacon Press. Tradução francesa em 1981,L'empire transsexual. Paris: Seuil.T. Szasz, o papa da antipsiquiatria publica resenha elogiosa do livro em New York Times Book Review (10 de junho), onde se escandaliza com os tratamentos cirúrgicos dos TS. PRINCE, C. Charles to Virginia: Sex Research as a Personal Experience. In: BULLOUGH, V. (ed.) The Frontiers of Sex Research. Buffalo: Prometheus Books. Primeiro uso do termo "transgender" pelo autor, que reivindica mudar de sexo sem operação dos órgãos genitais e se desmarca assim dos "transexuais”. MEYER, J.K. e Reter, D.J. Sex reassignment. Archives of General Psychiatriy, n. 36, pp. 1.010-1.015. Primeira revisão (negativa) das operações de Johns Hopkins, estudo que será muito criticado, causando oficialmente a interrupção das operações. LIMENTANI, A. The significance of transsexualism in relation to some basic psychoanalytic concepts. International Review of Psychoanalysis, n. 6, pp. 139153. IMPERATO-MACGINLEY, J.; PETERSON, R; GAUTIER, T. e 
STURLAS, E. Androgens and the evolution of male gender identity among male pesudo-hermaphrodites with 5-alpha-reductase deficiency. New England Journal of Medecine, $\mathrm{n}$. 300, pp. 1.233-1.237.

1980 A República Federal da Alemanha adota uma legislação sobre a mudança de sexo(10/9/1980, BGBI 1.s 1.654). Na República Democrática da Alemanha a legislação sempre foi mais leve. O principal centro é a clínica de Ependorf em Hamburgo, dirigida por Hans Giese. Sessão da Société médico-psychologique em Paris, consagrada ao transexualismo, onde os psiquiatras reivindicam sua inclusão no tratamento. A DSM III incorpora a definição do transexualismo como "gender identity disorder" (rubrica 302-5X) e, ao mesmo tempo, oficializa o desaparecimento da homossexualidade da lista das patologias. NOLAIS, J e RIHOIT, C. Histoire de Jeanne. Paris: Ed. Mazarine. O’ FLAHERTY, W.D. Women, Androgynes and Other Mythical Beasts. Chicago: University of Chicago Press. Texto de referência da antropologia indianista. ENGEL, W., PFAFFLIN, F. e WIDEKING. H-Y antigen in transexuality and how to explain testis differentiation in $\mathrm{H}-\mathrm{Y}$ antigen-negative males and ovary differentiation in antigen-positive females. Human Genetics, n. 55, pp. 315-319. FLEMING, M.;STEINMAN, C. e BROCKNEK, G. Methodological problems in assessing sex reassignment surgery. A reply to Meyer and Reter. Archives for Sexual Behavior, n. 9, pp. 451-456. HUNT, D.D. e HAMPSON,J. Transsexuals: A standardized psychosocial rating format for the evaluation of results of sex reassignment surgery. American Journal of Psychiatry, n. 137, pp. 432-438. MONEY, J. Love and Love sickness. The Science of Sex, Gender Difference and Pair Bonding. Baltimore: Johns Hopkins University Press. OPPENHEIMER, A. Le choix du sexe. Paris: PUF.

1981 VII Congresso da Harry Benjamin International Gender Dysphoria Association. Proposição de lei do senador Henri Cavaillet contra a discriminação em relação aos homossexuais e transsexuais. Science consagra o número 211 ao dimorfismo sexual, editado por NAFTOLIN, F., e BUTZ, E. HERDT, G. Guardians of the Flutes. New York: Mc GrowHill. Texto sobre a formação psicossociológica da masculinidade entre os Sambias de Papua - Nova Guiné. Livro básico da interpretação etnosociológica da identidade sexual. Robert Stoller havia em 1979 participado de sua pesquisa de campo. LUNDSTRÖM, B. Gender dysphoria. A SocialPsychiatric Follow-up Study of 31 Cases Non-Accepted for Sex-Reassignment. Universidade de Göteborg. SPRINGER, A. Pathologie der geschlechtlichen Identität. Transsexualismus und Homosexualität.Vien: Springer Verlag.

1982 Lei italiana sobre a mudança de sexo (n. 164, 14/4/1982), que deixa os tribunais apreciarem as condições necessárias. S. Satterfield apre- 
senta à reunião anual da American Psychiatric Association de San Francisco um estudo catamnésico sobre 22 pacientes operados na Universidade de Minnesota, concluindo com uma melhoria psicológica global. A Corte constitucional alemã abriga a disposição da lei de 1980 que interditava aos menores de 25 anos a mudança de sexo (o limite inferior é a idade da puberdade). BILLINGS, D. e URBAN, T. The socio-medical construction of transsexualism: an interpretation and critique. Social Problems, n. 3, pp. 266-282. BURZIG, G. Der Psychoanalytiker und der transsexuelle Patient. Ein Beitrag zur notwendigen Auseinandersetzung mit "psychochirurgischen Eingriffen na Geschlechtsmerkmalen”. Psyche, n. 36, pp. 848-856. CZERMAK, M. Précisions sur la clinique du transsexualism. Le discours psychanalytique, n.3, pp. 16-22. LOEB, L. e SHANE, M. The resolution of a transsexual wish in a five-year-old boy. Journal of the American Psychoanalytic Association, n. 30, pp. 419-434. LOTHSTEIN, L. Sex reassignment surgery: Historical, Bioethical and Theoretical Issues. American Journal of Psychiatry, n.39, pp.417-426. MEYER-BAHLBURG, H. Hormones and psychosexual differentiation: implications for the management of intersexuality, homosexuality and transsexuality. Clinics in Endocrinology and Metabolism, n. 11. MILLOT, C. Norsexe. Essai sur le transsexualisme. Paris: Point Hors Ligne.

1983 VIII Congresso da Harry Benjamin International Gender Dysphoria Association em Bordeaux. RICHARDS, Renée (nascido Richard Raskind). Second Serve: The Renée Richard Story. New York: Stein and Day. DULLAK, S. Je serai elle. Paris: Presses de la Cité. CHRISTA, G. Im falschen Körper gefangen. Report über eine Geschlechtsumwandlung. Munich: Wilhelm Heyne Verlag. LOTHSTEIN, L. Female-to-Male Transsexualism: Historical, Bioethical and Theoretical Issues. Boston: Routledge and Kegan Paul. PERSON, E e OSESEY, L. Psychoanalytic Theories of gender identity. Journal of the Academy of Psychoanalysis, n. 11, pp. 203-226.

1984 FOUCAULT, M. Histoire de la sexualité II: L'usage des plaisirs, e Histoire de la sexualité III: Le souci de soi. Paris: Gallimard. DIAMAND-BERGER, O. (ed.). Le transsexualisme. Droit et éthique médicale. Paris: Masson. REICHE, R. Sexualität, Identität, Transsexualität. Sexualtheorie und Sexualpolitik. Beiträge zur Sexualforschung, n. 59. Stuttgart: Enke. FAST, J.Gender Identity. Hillsdale: The analytic Press. EICHER, W. Transsexualismus: Möglichkeiten und Grezen der Gerschlechtsumwandlung. Stuttgart: Fischer. Referência sexológica essencial em língua alemã, reeditada em 1992.

1985 IX Congresso da Harry Benjamin Association em Minneapolis, onde John Money levanta a questão da apotemnofilia. Lei muito liberal nos Países-Baixos sobre a mudança de sexo. FAUSTO-STERLIN, A. 
Myths of gender: Biological Theories about Women and Men. New York: Basic Books. BRETON, J.; FROHWIRTH, C.; POTTIEZ, S; KINDINYS, S. Le transsexualismo: étude nosographique et médico-légale. Paris: Masson. HECKER, W.C. Surgical Correction of intersexual genitalia and female genital marlformation. Berlin: Springer. Referência padrão. STEINER, B.; BLANCHARD, R. e ZUCKER, K (ed.) Gender Dysphoria: Development, Research and management. New York: Plenum Press. Especialmente o artigo biologisante exemplar de J. Hoening, The origin of gender identity. STOLLER, R. Presentation of Gender. New Haven: Yale University Press.

1986 Morte de Harry Benjamin, aos 101 anos de idade. Fim do processo do belga Daniel van Oosterwyck, o primeiro transexual a conseguir aceitação na Cour Européenne des Droits de l'Homme e que tem permissão para modificar seu estado civil. Mas a CEDH se recusa a obrigar os Estados-membros a modificar o estado civil dos transexuais. No caso "Rees contra o Reino Unido", a CEDH estabelece no entanto que o casamento no sentido do artigo $12 \mathrm{da}$ Convenção visa às pessoas de sexo biológico diferente. Autorização de operações em Israel.WILLIAMS, W.L. The Spirit and the Flesh: Sexual Diversity in American Indian Culture. Boston: Beacon Press. Livro que reanimou o interessse pelos berdaches, reeditado em 1992. DOUCE, J. La question transsexual. Paris: Lumière et Justice. WALTERS, W. e ROSS, M. Transsexualism and Sex Reassignment. Oxford/London: Oxford University Press.

1987 X Congresso da Harry Benjamin Association em Amsterdã. Criação da International Foundation for Gender Education, primeira organização transexual militante, cuja revista, Tapestry, populariza as questões de gênero. Inclusão do transexualismo em DSM IIIR como "disforia de gênero", como causa para o "distúrbio de identidade de gênero" (i.e., o transexualismo). Primeira sentença da Corte Suprema espanhola autorizando as modificações das menções de sexo no estado civil. COCCINELLE. Coccinelle. Paris: Filippachi. MARIN, M. Le saut d'ange. Paris: Fixot. Publicação do ensaio de Theresa de Lauretis, Technologies of Gender: Essays on Theory, Film and Fiction. Bloomington: Indiana University Press. Roscoe, W. Bibliography of berdache and alternative gender roles among North American Indians. Journal of Homosexuality, n. 14, pp. 3-4. GREEN, R. The "Sissy Boy Syndrome" and the Development of Homosexuality. New Haven: Yale University Press. Resultados e discussões de um estudo catamnésico de 1975. HUBER,A. e HIERSCHE, H-D. Praxis der Gynäkologie im Kindes und Jugendalter. Stuttgart: Thieme.

1988 O relatório Braibant preconiza a abstenção legislativa em matéria de transexualismo, devido a problemas bioéticos e filosóficos insu- 
peráveis. Votação de uma resolução do parlamento europeu condenando a discriminação em relação aos transexuais e de uma recomendação (n. 1.117) apelando aos Estados-membros a retificar o estado civil dos transexuais "irreversíveis". A Turquia adota uma lei sobre a mudança de sexo (n. 3444 de 4/5/1988). Na Polônia, por outro lado, a Corte Suprema consagra uma reviravolta de jurisprudência que interdita mudança do sexo mencionado no estado civil. BOLIN, A. In search of Eve: Transsexual Rites of Passage. South Hadley: Bergin and Harvey. A análise sociológica dos transexuais começa a revelar a plasticidade de seus relatos justificativos em função das ofertas medicinais (notadamente por Richard Docter). Início da campanha pela despatologização do transexualismo. CHILLAND, C. Enfance et transsexualisme. La psychiatrie de l'enfant, n. 31-2, pp. 313-373. DOCTER, R. Transvestiters and Transsexuals: Toward a Theory of Cross-Gender Behavior. New York: Plenum Press. Claramente biologizante. LIMENTANI, A. To the limits of male heterosexuality. The vagina-man. Journal of Analytic Psychology and Psychopathology, n. 2, pp. 115-129.

1990 Louis Gooren é nomeado para a primeira cátedra médica consagrada oficialmente ao transexualismo na Vrije Universitat de Amsterdã. Nova recusa da CEDH de obrigar os Estados-membros a modificar o estado civil dos transexuais. O Reino Unido, que não dá nenhum estatuto legal ao transexualismo, escapa à condenação incisa no artigo 8, nos casos "Rees" e "Cossey". Muitos ensaios feministas críticos e históricos sobre a questão da diferença sexual, notadamente LAQUEUR,T. Making Sex: Body and Gender from the Greeks to Freud. Cambridge, Harvard University Press. BUTLER, J. Gender Trouble: Feminism and the Subsversion of Identity. New York: Routledge. IRVINE, J. Disorders of Desire: Sex and Gender in Modern American Sexology. Philadelphia: Temple University Press. OUDSHOORN, N. On the making of sex hormones: research materials and the production of knowledge. Social Studies of Science, n. 20. KESSLER, S. The medical construction of Gender: Case management on intersexed infants. Signs: Journal of Women in Culture and Society, n. 1, pp. 5-40. EPSTEIN, J. Either/or - neither/both: sexual ambiguity and the ideology of gender. Gender, n. 7, pp. 100-142. As duas últimas são contribuições decisivas para a retomada da questão das evidências médicas relativas à intersexualidade. Enfim, a importantíssima contribuição antropológica de NANDA, S. Neither Man or Woman: The Hijras of India. Belmont: Wadsworth.

1991 Morte acidental de Robert Stoller. Morte de Christine Jorgensen. Condenação da França pela Corte européia de Strasbourg, no caso Betella, operado sob solicitação em Casablanca, em 1972, por Georges Burou, e a quem tinha sido recusada a mudança de estado civil. A Polô- 
nia chega ao reconhecimento legal do transexualismo. EPSTEIN, J. e STRAUB, C. Body Guards: The Cultural Politics of Gender Ambiguity. New York: Routledge. Nesta obra destaca-se STONE, S. The Empire strikes back. A posttranssexual manifesto (pp. 280-304). DIMEN, M. Desconstructing difference: Gender, splitting and "transitional space". Psychoanalytic Dialogues, n. 1, pp. 249-272. KAMPRAD, B. e SCHIFFELS, W. Im falschen Körper: Alles über Transsexualität. Zurich: Kreuz. HABER, C.K. The psychoanalytic treatment of a preschool boy with transsexual symptoms. Journal of the American Psychoanalytic Association, n. 39, pp. 107-129. LOEB, L. R. Analysis of the transference neurosis in a child with transsexual symptoms. Journal of the American Psychoanalytic Association, n. 40, pp. 587-605. MEYER, W.S. e KEITH, C.R. Homosexual and preoedipal in the psychoanalytic psychotherapy of a female-to-male transsexual. In: SOCARIDES, C. e VOLHAM, V. (ed.). The Homosexualities and the Therapeutic Progress.

1992 A Corte de cassação modifica a jurisprudência de 1975 sobre a indisponibilidade do estado da pessoa após a condenação da França pela CEDH no "caso Botella" (Bulletin des Arrêts de la Cour de Cassation, 1/2/1993, n. 13, p. 27). PETTITI, J. Le transsexualism. Paris: PUF. HAUSMAN, B. Demanding subjectivity: Transsexualism, medicine, and the technologies of gender. Journal of the History of Sexuality, n. 3, pp. 270-301. Em outubro, resposta de Bernice Hausman a Vern Bullough. FEINBERG, L. Transgender Liberation: a Movement whose Time Has Come. New York: World View Forum. Clássico do militantismo transgenerista. KAMERMANS, J. Mythos Geschlechtswandel: Transsexualität und Homosexualität. Hambourg: Hathor. PFÄFFLIN, F.e JUNGE, A. Geschlechtumwandlung Schattauer. Estudo denso dos resultados das operações. SIGUSH, V. Geschlechtswechsel. Hambourg: Klein. Contraponto do transexualismo ao clássico MORGENTHALER. Homosexualität, Heterosexualität, Perversion, de 1984.

1993 O romance-ícone de L. Feinberg, Stone Butch Blues, é publicado por Firebrand, Ithaca. Fundação da Intersex Society of North America por Cheryl Chase, que milita contra a redefinição sexual obrigatória dos hermafroditas e lança o boletim Hermaphrodites with an attitude. S. Le Vay, militante homossexual, publica The Sexual Brain, Boston: MIT Press, que fornece os métodos da polêmica sobre o cérebro transexual. HIRSCHAUER, S. Die Soziale Konstruktion der Transsexualität: Über die Medizin und den Geschlechtswechsel. Frankfurt: Suhrkamp. LINDEMAN, G. Das paradoxe Geschlecht: Transsexualität im Spannungsfeld von Körper, Leib und Gefühl.Frankfurt: Fischer. BRANLARD, J.P. Le sexe et l'état des personnes. Paris. Suma histórica e técnica sobre as questões de direito e transexualismo na França e na Europa. BULLOUGH, V. e BULLOUGH, B. Cross-Dressing, Sex and 
Gender. Philadelphia: University of Pensylvania Press. BUTLER, J. Bodies that Matters: on the Discursive Limits of Sex. New York: Routledge. FAUSTOSTERLING, A. The five sex: why male and female is not enough. The Sciences, pp. 20-25. GOOREN, L. Biological aspects of transsexualism and their relevance to its legal aspects. Actes du XXIIIème Colloque sur la loi européenne: Transsexualisme, Médecine et Droit. Strasbourg: Conseil de l'Europe. Argumentação biológica na perspectiva do sexo cerebral de Le Vay. PFÄFFLIN, F. Transsexualität: Beiträge zur Psychopathologie, Psychodynamik und Verlauf. Stuttgart: Enke.

1994 Em DSM IV, o "distúrbio da identidade de gênero" torna-se uma simples forma de uma "disforia de gênero" muito geral. HERDT, G (ed). Third Sex Third Gender. New York: Zone Books. OUDSHOORN, N. Beyond the natural Body: An Archeology of Sex Hormones. London: Routledge. KAMERMANS, J. Künstliche Geschlechter: Nirwana oder Götterdämmerung? Hamburg: Hathor. Publicação do manifesto "transgenerista” de K. Bornstein, On Men Women and the Rest of Us. New York: Routledge. STRYKER, S. My words to Victor Frankenstein above de village of Chamounix: Performing transsexual rage. Gay, Lesbian and Queen, n. 1, PP. 237-254. SALAS, D. Sujet de chair, sujet de droit. La justice face au transsexualisme. Paris: PUF. MERCADER, P. L'illusion transsexuelle. Paris: L'Harmattan. Revisão crítica cuidadosa das teses vigentes. MONEY, J. The concept of gender identity disorder in childhood and adolescence after 39 years. Journal of Sex and Marital Therapy, n. 20, pp. 163-177.

1995 HAUSMAN, B. Changing Sex: Transsexualism, Technology and the Idea of Gender. Duke University Press. Pratt, M.B. S/He. Ithaca: Firebrand. Trata-se de coletânea da poetisa lésbica. ROTHBLATT, M. The apartheid of Sex: A Manifesto on the Freedom of Gender. New York: Harper e Collins. O livro de J. Raymond, The Transsexual Empire, é reeditado por Columbia University Press, de New York, com um novo prefácio sobre o movimento transgenerista. WILKINS, R.A. Denial, dissociation \& transexuality as incest. Chrysalis, n. 2, pp. 39-45. STEIN, R. Analysis of a case of transsexualism. Psychoanalytic Dialogues, n. 5, pp. 257-289, seguido de CHODOROW, N. Multiplicities and Uncertainties of gender - Commentary on Ruth Stein's “Analysis of a case of transsexualism”, pp. 291-299; e de STEIN, R. Reply to Chodorow, pp. 301-310. SUPAR, M. A clinical approach to childhood gender identity disorder. American Journal of Psychotherapy, $n$. 49. SWAAB, D.F. e HOFFMAN, M. A. Sexual differentiation of the human hypothalamus in relation to gender and sexual orientation. Trends in Neurosciences, $\mathrm{n}^{\circ}$ 18, pp. 264-270. ZHOU, J.N.; HOFFMAN, M.A.; GOOREN, L e SWAAB, D.F. A sex difference in the human brain and 
its relation to transsexuality. Resposta de S. M. BREEDLOVE, Another important organ. Nature, n. 378, pp. 68-70. Início da polêmica sobre a base da stria terminalis no hipotálamo de transexuais.

\section{NOTAS}

${ }^{1}$ VON KRAFFT-EBING,Richard. Psychopathia sexualis, edição de 1923 por Albert Moll. E-mail do autor: pierrehenri.castel@free.fr Tradução deste artigo por Teresa Malatian.

${ }^{2}$ Quantos transexuais existem hoje? Não se sabe. As estimativas oscilam devido à antiguidade das práticas clandestinas e da vontade da imensa maioria dos (as ) operados (as) de desaparecer no anonimato, uma vez modificado seu estado civil. Haveria cerca de 50.000 nos Estados Unidos e 3.000 na França.

${ }^{3}$ HAUSMAN,Bernice. Changing Sex: Transsexualism, Technology and the Idea of Gender. Duke University Press, 1995.

${ }^{4}$ BENJAMIN, Harry. The Transsexual Phenomenon. New York: Julian Press, 1966.

${ }^{5}$ BUTLER, Judith. Bodies that Matters: On the Discursive Limits of Sex. New York: Routledge, 1993.

${ }^{6}$ Observação $\mathrm{n}^{\mathrm{o}}$ 129, tradução nova de Henry Frignet e Françoise Bernard em Sur l'identité sexuelle: A propos du transsexualisme, editado por Henry Frignet e Marcel Czermak, vol. 1, Editions de l' Association Freudienne Internationale, Paris, 1996, pp. 243-309.

${ }^{7}$ BERMAN, Louis. The Glands Regulating Personality. New York: Mac Millan, 1928. ROBINSON, Williams. Our Mysterious Life Glands. How they affect us. New York: Eugenics Publishing, 1934. FRANK, R. The Female Sex Hormone. Springfield: Charles Thomas, 1929. De KRUIF, Paul. The Male Hormone. New York: Arcourt Brace, 1945.

${ }^{8}$ Bantig e MacLeod em 1923, Dale em 1936, Butenandt em 1939, o único que o obtém não em medicina, mas em química, Doisy em 1943, por trabalhos empreendidos desde 1920.

${ }^{9}$ TRIDON,André. Psychoanalysis and Gland Personalities. New York: Brentano, 1923.

${ }^{10}$ HOYER, Nils. Man into Woman: An Authentic Record of a Change of Sex. London: Jarrolds; New York: Dutton, 1933.

${ }^{11}$ GILLIES, Harold e MILLARD, Ralph. Principles and Art of Plastic Surgery. Boston: Little \& Brown; LONDON: Butterworth, 1957.

${ }^{12}$ DILLON, Michael. Self: A Study in Ethics and Endocrinology. London: Heinemann, 1946.

${ }^{13}$ YOUNG, Hugh. Genital Abnormalities, Hermaphroditism and Related Adrenal Disorders. Baltimore: Williams and Wilkins, 1937.

${ }^{14}$ OSTOW, M.K. Letter to the Editor. Journal of the American Medical Association, $\mathrm{n}$. 152, pp. 1.553, 1953; KUBIE, L.S. e MACKIE, J.B. Critical issues raised by operations for gender transmutation. Journal of Nervous and Mental Diseases, n. 147, 
pp. 331-343, 1968, e sobretudo STOLLER, Robert. A biased view of "sex transformation" operations (editorial). Journal of Nervous and Mental Diseases, n. 149, pp. 312-317,1969.

${ }^{15}$ Além disso, é constante que os textos psicanalíticos que indicam as possibilidades de uma tal psicoterapia sejam considerados como marginais, ou politicamente enviesados por aspirações reacionárias. O descrédito dos trabalhos de Lothstein (1983) não tem nada a ver com sua qualidade científica, mas com seu estatuto psicanalítico.

${ }^{16}$ GUTHEIL, Emil. The psychoanalytic background of transsexualism and transvestism. American Journal of Psychotherapy, n. 8, 1954.

${ }^{17}$ COWELL,Roberta. Roberta Cowell's Story.New York: British Book Centre, 1954; STAR, Hedi Jo. I Changed my Sex, 1955. JORGENSEN, Christine. A Personal Autobiography. Forest Dale: Paul Eriksson, 1967; VIDAL,Gore. Myra Breckinridge. Boston, 1968 e MORRIS, Jan. L"énigme. D'un sexe à l'autre. Paris: Gallimard, 1974.

${ }^{18}$ FISK, Norman. The how, the what, the why of a disease. In: LAUB, D. e GANDY, P. (ed.). Proceedings of the second interdisciplinary symposium on gender dysphoria syndrome. Palo Alto: Stanford University Press, 1973. A paternidade da idéia é sem nenhuma dúvida de Money.

${ }^{19}$ PRINCE, Charles F./Virginia. Charles to Virginia: Sex Research as a Personal Experience. In: BULLOUGH, Vern (ed.). The Frontiers of Sex Research. Buffalo: Prometheus Books,1979.

${ }^{20}$ RAYMOND, Janice. The Transsexual Empire: The Making of the She-Male. Boston: Beacon Press, 1979.

${ }^{21}$ A fundação Reed Erikson é o tipo da organização de primeira geração: subvencionada a partir de 1964 por um transexual que se tornou milionário, amigo e antigo paciente de Harry Benjamin, ela difundiu em grande escala manuais e conselhos práticos para ajudar os candidatos à transexualização; ela sustentou também os primeiros passos da Harry Benjamin International Gender Dysphoria Association (HBIGDA), cujos "Standards of Care" para os transexuais são os mais adotados no mundo. Mais liberal, a International Foundation for Gender Education (IFGE), que editou Tapestry, a grande revista transgender, busca baixar a coação desses "Standards".

${ }^{22}$ CHASE,Cheryl. Hermaphrodites, 1993.

${ }^{23}$ LE VAY, Simon. The Sexual Brain. Boston: MIT Press, 1993.

${ }^{24}$ ZHOU, J.N.; HOFFMAN, M. A.; GOORER, L. e SWAAB, D.F. Sexual differentiation of the human hypothalamus in relation to gender and sexual orientation. Trends in Neurosciences, n. 18, pp. 264-270, 1995.

${ }^{25}$ CHILAND, Colette. Enfance et transsexualisme. La psychiatrie de l'enfant, n. 31, pp. 313-373, 1989; CZERMAK, Marcel. Précisions sur la clinique du transsexualisme. Le discours psychanalytique, n. 3, pp. 16-22, 1982; LIMENTANI, Adam. To the limits of male heterosexuality. The vagina-man. Journal of Analytic Psychology 
and Psychopathology, n. 2, pp. 115-129, 1989; MILLOT, Catherine. Horsexe. Essai sur le transsexualisme. Paris: Point Hors Ligne, 1982; OPPENHEIMER, Agnès. Le choix du sexe. Paris: PUF, 1980; STEIN, Ruth. Analysis of a case of transsexualism. Psychoanalytic Dialogues, n. 5, pp. 257-289, 1995.

${ }^{26}$ Contribuíram para o estabelecimento desta cronologia Heike Boedeker, Bernice Hausman e Geneviève Morel.

Artigo recebido em 01/2001. Aprovado em 03/2001. 